\title{
Motor activity in the large intestine of the pig related to dietary fibre and retention time
}

\author{
BY J. FIORAMONTI AND L. BUENO \\ Laboratoire de Physio-Pathologie Digestive INRA, \\ Ecole Nationale Vétérinaire, 31076 Toulouse Cédex, France
}

(Received 9 April 1979-Accepted I6 July 1979)

\begin{abstract}
1. Large intestine electromyograms were recorded from four pigs receiving successively three diets containing different amounts of fibre (standard cereal diet, milk substitute and milk plus $170 \mathrm{~g} \mathrm{bran} / \mathrm{kg}$ ). For each diet the mean retention time of a marker added to one meal was determined. Three occurrences of spontaneous constipation were also studied.

2. Slow waves were observed in the colon only during $10 \%$ of the recording time at a frequency of $10.3 \pm$ $\mathrm{I} \cdot \mathrm{I} / \mathrm{min}$. Two kinds of spiking activity were recorded on the colon: short spike bursts of $0.5-2 \mathrm{~s}$ duration and long spike bursts of approximately $7 \mathrm{~s}$ duration. Long spike bursts alone were recorded on the caecum.

3. The mean retention time of the marker was $40 \mathrm{~h}$ on the standard diet, $120 \mathrm{~h}$ on the milk-substitute diet, and $66 \mathrm{~h}$ on the milk plus bran diet.

4. On the standard diet, approximately 1500 colonic long spike bursts were recorded daily and short spike bursts occupied $15 \%$ of the recording time. On the milk diet, the number of long spike bursts decreased significantly $(P<0.01)$ to $500 / \mathrm{d}$ and the short spike bursts increased significantly $(P<0.05)$ to take up to $21 \%$ of the time. Intermediate values ( $1100 / d$ and $19 \%$ ) were observed when bran was added to the milk diet. The lowest values for long spike bursts (300/d) and highest values for short spike bursts $(44 \%$ of the time) were observed in constipation.

5. It is concluded that long spike bursts are associated with propulsion of intestinal contents and that short spike bursts are non-propulsive.
\end{abstract}

The relationships between colonic motility patterns and the movement of intestinal contents have been investigated in diarrhoea, constipation and diverticular disease in humans (Connell, 1962; Kirwan \& Smith, 1975). Diarrhoea corresponds for its most severe phase to colonic hypomotility and constipation paradoxically to hypermotility. The digestive transit time depends on dietary fibre, and bran consumption is likely to be the most effective way of shortening prolonged transit time on low-residue diets (Cummings et al. 1978; Heaton et al. 1974).

That dietary fibre acts on colonic motility is well established, but the relationships between changes in transit time and colonic motility patterns are still unknown. In pigs, the retention time of a marker in the digestive tract can be modified from 40 to $\mathrm{I} 20 \mathrm{~h}$ by varying the level of dietary fibre (Canguilhem \& Labie, 1977) and it is presumably related to the time spent by digesta in the large intestine since this represents approximately $80 \%$ of the total mean transit time (Keys \& De Barthe, 1974).

The purpose of this study was to determine in pigs the relationships between the patterns of myoelectric colonic activity already studied by electromyography in normal and megacolon pigs (Fioramonti \& Bueno, 1977) and the transit time of digesta for three diets in which the cellulose level was modified.

\section{MATERIALS AND METHODS \\ Animals and diets}

Four Large White pigs, 5 months old and weighing approximately $50 \mathrm{~kg}$ at the beginning of the experiments were used. They were housed in individual cages. Three diets were given: standard concentrates of barley, wheatings and fish meal (Rental, 31770 Colomiers), milk 
Table I. Chemical composition of diets ( $\mathrm{g} / \mathrm{kg}$ dry matter)

$\begin{array}{lccc} & \begin{array}{c}\text { Standard } \\ \text { concentrates }\end{array} & \begin{array}{c}\text { Milk } \\ \text { substitute }\end{array} & \text { Milk + bran } \\ \text { Cellulose } & 57 & - & 23 \\ \text { Hemicellulose } & 73 & 3 & 48 \\ \text { Lignin } & 17 & - & 9 \\ \text { Crude protein (nitrogen } \times 6.25) & 161 & 241 & 222 \\ \text { N-free extract } & 590 & 447 & 433 \\ \text { Lipid } & 27 & 212 & 179 \\ \text { Minerals } & 75 & 97 & 86\end{array}$

(powdered milk-substitute; Serval, $79 \mathrm{La}$ Mothe St-Heray) and milk $(830 \mathrm{~g} / \mathrm{kg}$ dry matter, DM) plus bran ( $170 \mathrm{~g} / \mathrm{kg} \mathrm{DM})$. The chemical composition of the diets is given in Table $\mathrm{I}$. The four animals received each diet for successive periods of $20 \mathrm{~d}$. A daily meal consisting of $\mathrm{I} .5 \mathrm{~kg}$ DM food added with water (I l) was given at 09.00 hours. Throughout the experiment, water was available $a d l i b$. and its mean consumption (1/d) was $3 \cdot I \pm 0 \cdot 4$ on the standard diet, $5.4 \pm 0.7$ on the milk diet and $5 \cdot 2 \pm 0.9$ when bran was added to milk.

\section{Myoelectrical records}

Under halothane anaesthesia, stainless-steel electrodes were implanted in groups of three, $2 \mathrm{~mm}$ apart, on the terminal ileum, the caecum, the centripetal and the centrifugal turns of the ascending colon, the transverse colon and the descending colon. Two other groups were implanted, one on the pyloric antrum and the other on the mid-jejunum. In two pigs, three additional groups were implanted at $100 \mathrm{~mm}$ intervals on the third centripetal turn of the ascending colon. Commencing $6 \mathrm{~d}$ after surgery, electrical activity was recorded for a period of 8 weeks using an eight-channel 'direct writing' polygraph (Reega VIII; Alvar Electronic, 93 Montreuil) at a recording speed of $45 \mathrm{~mm} / \mathrm{min}$ with a time constant of 0.1 s. Concurrent summation, at $20 \mathrm{~s}$ intervals, of the electrical activity from four electrode sites (ileum, caecum, centripetal and centrifugal turns of the ascending colon) was obtained by a linear integrator circuit connected to a four-channel potentiometric recorder (Latour, 1973). Integrations were used $24 \mathrm{~h} / \mathrm{d}$ as a monitoring procedure throughout the experiment. Myoelectrical activity was analysed from the original electromyograms continuously recorded over $3 \mathrm{~d}$ during the measurement of transit times on each diet. Direct records were also continuously obtained during three occasional periods of spontaneous constipation in two pigs on milk diet.

\section{Transit time}

To measure the retention time of food residues in the digestive tract, a marker was added in one meal of each diet in the four animals, $10 \mathrm{~d}$ after the beginning of records or $10 \mathrm{~d}$ after changing the diet. The marker consisted of fifty small, flexible discs, approximately $3 \mathrm{~mm}$ diameter and $0.3-0.5 \mathrm{~mm}$ thick, of coloured polyvinyl chloride. Faeces were collected continuously during $7 \mathrm{~d}$ after dosing on a conveyor belt $(200 \mathrm{~mm} / \mathrm{h})$ under the animal's cage. Thus the time of defaecations was given with a \pm 15 min precision. The excretion of marker was recorded $v$. time and the mean retention time was calculated according to Castle (1956).

\section{RESULTS}

Motility patterns and retention time on the standard diet

The mean retention time of the marker was $40^{\circ} 5 \pm 3^{\cdot 2} \mathrm{~h}$. Slow waves were not recorded from the caecum, while the colon and especially its distal part exhibited slow waves of 
(a)

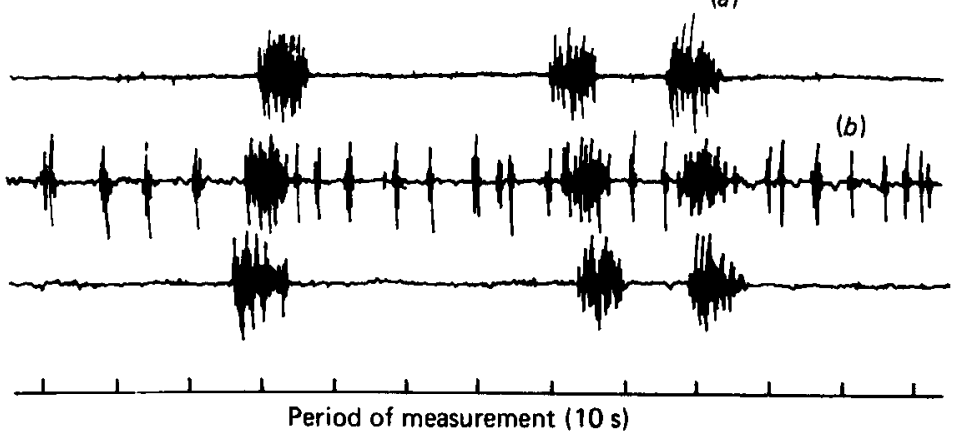

Fig. I. Major patterns of colonic electrical spiking activity. The electrode sites were $100 \mathrm{~mm}$ distant on the third centripetal turn of the proximal colon; the pig was given a standard concentrate diet (for details, see Table $\mathrm{t}$ ). (a) Three long spike bursts with a duration ranging between 8 and $15 \mathrm{~s}$ and propagated in aboral (Ist and 2nd) or oral (3rd) direction between the three electrode sites: (b) short spike bursts, $I-2 \mathrm{~s}$ in duration, non-propagated over two electrode sites.

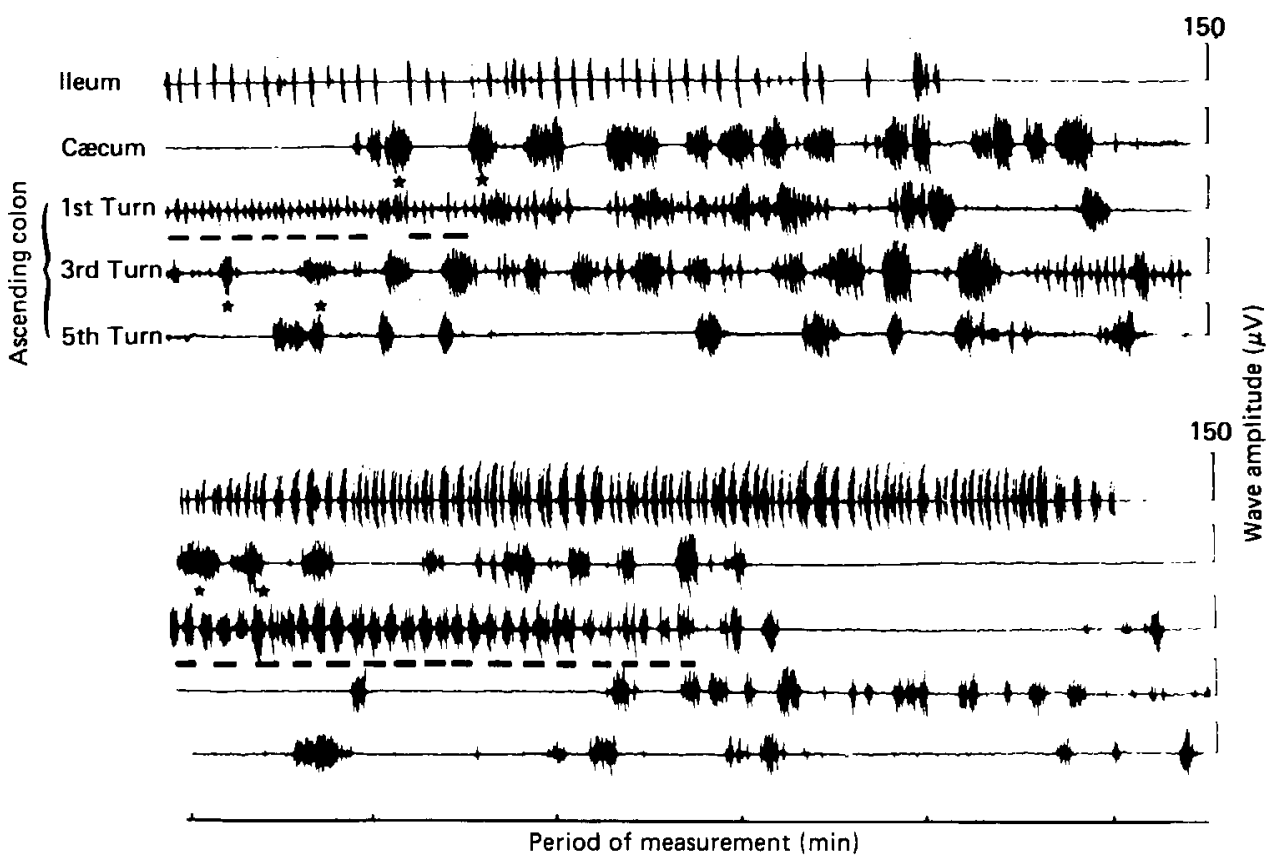

Fig. 2. Ileo-caeco-colonic electromyograms for a pig given a standard concentrate diet (for details, see Table 1 ). The two patterns of electrical spiking activity are shown on the ascending colon: short spike bursts (--) and long spike bursts $\left(^{*}\right)$ similar to those seen on the caecum. A period of short spike bursts is recorded on the proximal colon when the regular spiking activity phase of a migrating complex reached the terminal ileum.

very low amplitude $(20 \mu \mathrm{V})$ at a mean frequency of $10.3 \pm \mathrm{I} \cdot \mathrm{l} / \mathrm{min}$ during approximately $10 \%$ of the time. As previously described (Fioramonti \& Bueno, 1977), the electromyogram of the caecum showed spike bursts of approximately $10 \mathrm{~s}$ duration, grouped into 10-15 phases lasting $4 \mathrm{~min}$ and occurring at a mean frequency of $4 / \mathrm{h}$. In the ascending colon, two patterns of electrical spiking activity were recorded (Fig. I): (I) long spike bursts identical to those observed in the caecum, grouped in phases less delimited than but associated with the 
Table 2. Spiking activity of the proximal colon (daily number of long spike bursts and total duration of spiking activity as short spike bursts), mean retention time and nature of the faeces of pigs given three diets containing different amounts of fibre

(Mean values with their standard errors for four animals)

Diet $†$

Long spike bursts (no./24 h)

Short spike bursts ( $\mathrm{min} / 24 \mathrm{~h}$ )

Mean retention time (h)

Faeces wt (g/24 h)

Faeces dry matter $(\mathbf{g} / \mathbf{k g})$

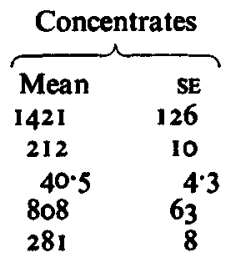

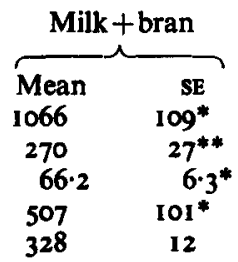

\begin{tabular}{|c|c|}
\hline \multicolumn{2}{|c|}{ Milk } \\
\hline Mean & SE \\
\hline 516 & $85^{* *}$ \\
\hline 306 & $33^{* *}$ \\
\hline 120.3 & $9 \cdot 6^{*}$ \\
\hline 196 & $97^{* *}$ \\
\hline 375 & 14 \\
\hline
\end{tabular}

Values were significantly different from those for concentrate diets: $* P<0.05, * * P<0.01$. † For details, see Table I.

caecal phases; the propagation of these bursts in both directions at a speed of $83 \pm 25$ $\mathrm{mm} / \mathrm{s}$ was clearly observed between two electrode sites at less than $200 \mathrm{~mm}$ intervals (Fig. I). Their propagation over longer distances was equivocal; (2) short spike bursts (0.5-2 s duration) recurring at a frequency ranging between 9 and $12 / \mathrm{min}$; they were not propagated, at least over distances exceeding $100 \mathrm{~mm}$; this activity seemed to be independent of the long spike bursts and was observed at a single electrode site or simultaneously at several levels of the proximal colon (Fig. 2). During the propagation of a phase of regular spiking activity (myoelectric complex, MMC) along the last $\mathrm{I} \mathrm{m}$ of the ileum (see Ruckebusch \& Bueno, 1976), the short spike bursts sometimes became longer (3 s), recurring at a frequency of $11 \cdot 8 \pm 0 \cdot 6 / \mathrm{min}$ for $3-5 \mathrm{~min}$. This reinforced activity was observed only during an ileal MMC and was restricted to one electrode site on the proximal colon. The electrical activity of the transverse and descending colon was very similar to that observed on the ascending colon except that the cyclic phases of activity were less discrete. The short spike bursts did not present any relationship with feeding.

\section{Retention time and colonic motility on a milk diet}

On the milk diet, the mean retention time of the marker increased to $120.3 \pm 9.6 \mathrm{~h}$ (Table 2 ). The daily weight of faeces was only $26 \%$ of that observed on the standard diet and their DM increased from $28 \mathrm{I} \pm 8$ to $375 \pm \mathrm{I} 4 \mathrm{~g} / \mathrm{kg}$.

The daily number of caecal spike bursts remained unchanged in the region of the ileo-

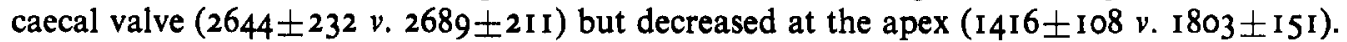
The major changes appeared in the colon (Table 2, Fig. 3): in the ascending colon the number of long spike bursts decreased from $I 42 I \pm I 26 / d$ to $516 \pm 85 / d$ and the total daily duration of spiking activity as short bursts increased from $219 \pm 19$ to $305 \pm 33 \mathrm{~min}$. The phases of reinforced short spike bursts corresponding to the occurrence of an MMC on the terminal ileum remained unchanged.

The only modification observed in the upper part of the digestive tract was a reduced spiking activity of the antrum $(17.5 \pm 3.6 \%$ of slow waves with spike bursts superimposed v. $32.4 \pm 6.2 \%$ ). The frequency of $\mathrm{MMC}$ and the duration of the postprandial disruption in the small bowel were not modified.

\section{Effects of dietary fibre}

When the diet comprised $(\mathrm{g} / \mathrm{kg}) 170$ bran and 830 milk, the mean retention time of marker decreased to $66.2 \pm 6.3 \mathrm{~h}$ (Table 2), the daily faeces weight was more than doubled, and faeces DM was reduced from 375 to $328 \mathrm{~g} / \mathrm{kg}$. 


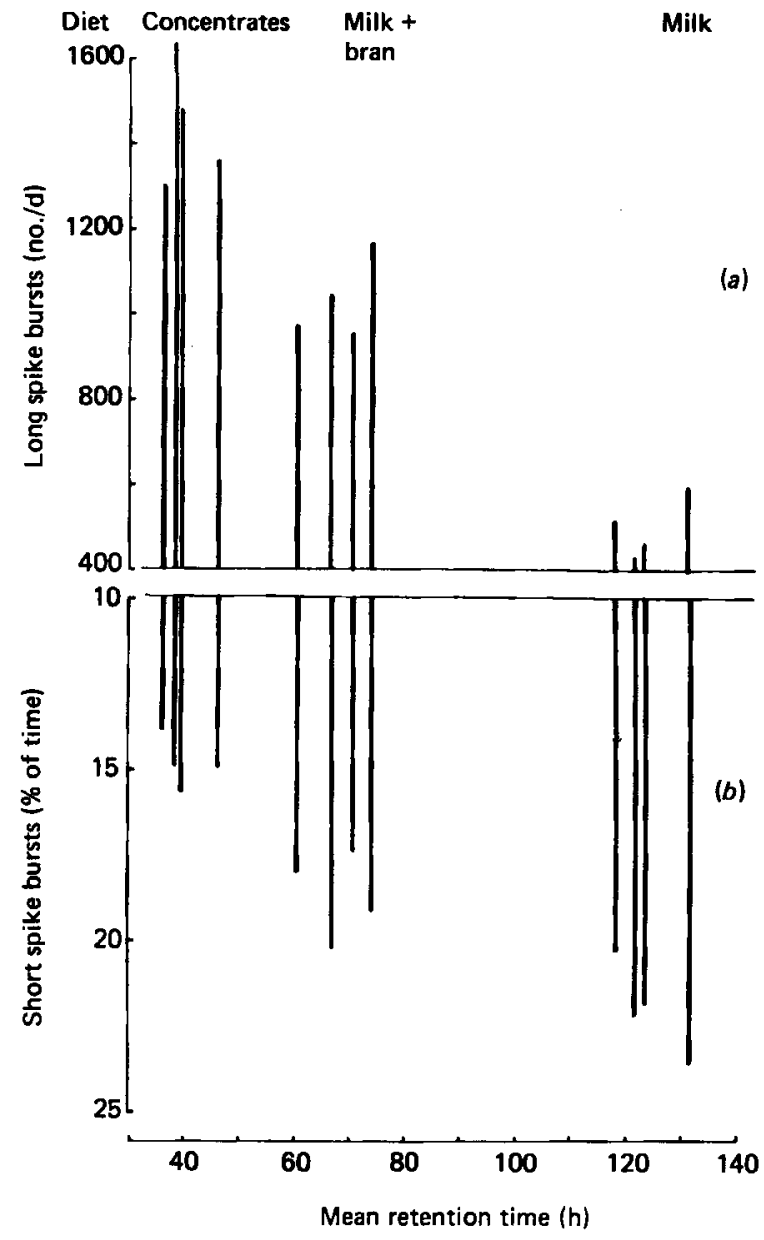

Fig. 3. Relationship between transit time (h) and colonic spiking activity. Vertical lines indicate the daily number of long spike bursts $(a)$ and the percentage of time during which short spike bursts occurred $(b)$. Values are for three consecutive days in one pig for each of three diets containing different amounts of fibre (for details, see Table I).

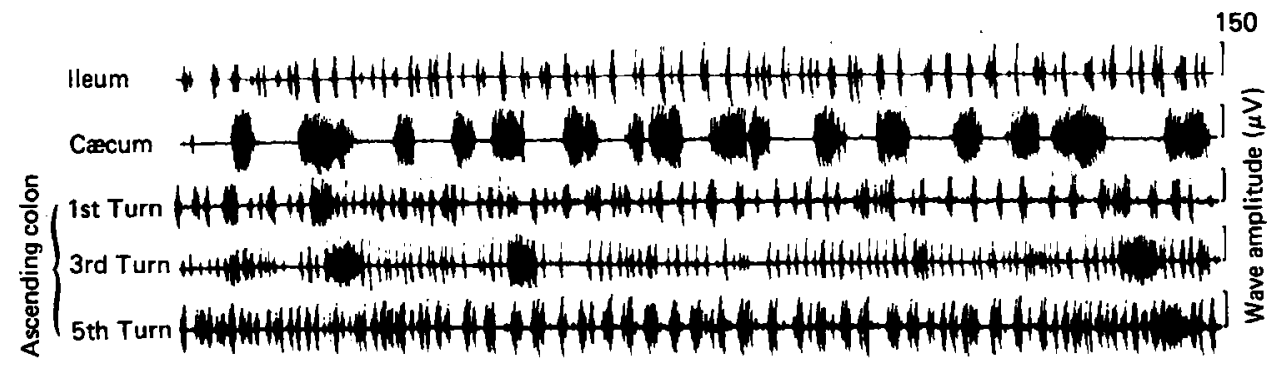

Period of measurement (min)

Fig. 4. Electrical activity during constipation in the pig. The caecum is more active and short spike bursts predominate in the colon 
Except for the base of the caecum where the number of bursts of spikes remained unchanged on the three diets, all measurements of caeco-colonic motility had values intermediate between those observed on the concentrate diet and the milk diet: $1678 \pm$ I 13 long spike bursts/d at the apex of the caecum, and $1066 \pm 109 / \mathrm{d}$ at the ascending colon with 270 min of spiking activity as short bursts/d.

In the proximal digestive tract spiking activity was virtually identical to that observed on the standard concentrate diet: $39.8 \pm 7.1 \%$ of antral slow waves superimposed by bursts of spikes, $14.6 \pm \mathrm{I} \cdot 2 \mathrm{MMC} / \mathrm{d}$ in the duodenum and jejunum, $3.7 \pm 0.6 \mathrm{~h}$ of postprandial disruption.

\section{Instances of constipation}

Spontaneous constipation appeared on the milk diet once in one pig and twice in another pig. It was characterized by a lack of defaecation for $50-78 \mathrm{~h}$ and anorexia during I or $2 \mathrm{~d}$ (Fig. 4).

A high level of spiking activity was observed in the caecum : $1987 \pm 103$ bursts of spikes at the apex and $3072 \pm 121$ at the base. The number of long spike bursts decreased dramatically in the proximal colon to $314 \pm 36 / \mathrm{d}$ and the total duration of spiking activity as short bursts increased to $636 \pm 41 \mathrm{~min}$. Moreover, supplementary phases $\left(5^{-10} /\right.$ day $)$ of reinforced spiking activity appeared without relationship to the propagation of $\mathrm{MMC}$ in the terminal ileum. Like normal phases, these supplementary phases did not occur simultaneously throughout the entire proximal colon but generally on only one turn or on two turns at the most.

\section{DISCUSSION}

The most striking result of this study was the observation that the electromyogram of the pig's colon is characterized by two kinds of spiking activity, short and long bursts of spikes. The relationship between the mean retention time of a marker and the number of long or short spike bursts/d suggests a propulsive function of the long spike bursts, while short spike bursts would be non-propulsive. This hypothesis is supported by the migrating form of long spike bursts and the localized and non-propagated appearance of short spike bursts.

However, two questions remain before validation of this study: (I) what is the correspondence between the bursts of spikes described here and the propulsive or segmental contractions classically described (Misiewicz, I975)?; (2) were the modifications of transit time of the marker from mouth to anus related only to the colonic motor changes?

The short spike bursts can be associated with segmental contractions and compared with type I pressure waves of the human colon (Spriggs et al. I95I) or type I contractions recorded by strain-gauges in the rabbit's proximal colon (Clauss et al. 1978): the mean frequency of these mechanical events ( $12 / \mathrm{min}$ in humans and $16 / \mathrm{min}$ in rabbits) corresponds to the slow-wave frequency observed in the pig.

In addition, phases of reinforced short spike bursts present a striking similarity with hypersegmentation detected with pressure records in humans. This activity appeared in patients with or without abdominal pain, and Misiewicz (1975) supposed that 'the hypersegmentation may be focal in distribution and out of reach of pressure-sensing devices'. This hypothesis is verified in the pig, in which phases of reinforced spiking activity appeared only at any one electrode site. Thus, in humans, hypersegmentation has been observed rarely owing to the use of only one recording device for short periods. In this experiment, hypersegmentation was readily detected owing to the greater number of electrode sites (four) and the continuous records made $24 \mathrm{~h} / \mathrm{d}$.

In general reviews on colonic motility in humans (Misiewicz, I975; Connell, I968), propulsive contractions were associated with mass movements which were rarely observed, 
and only in radiological studies. These mass movements can be compared to the strong bursts of spikes rapidly propagated from the ileum to the caecum and colon in pigs and occurring randomly at a mean frequency of $\mathrm{I} \cdot 3-2 / \mathrm{h}$ (Fioramonti \& Bueno, 1977). The long spike bursts described in this paper may correspond to type II or III pressure waves also considered as segmental contractions (Connell, 1968). However, direct comparison of the electrical activity described in this study with the pressure waves classically described in humans is difficult owing to interspecific and technical differences.

The correlation between the motility of the large intestine only and the whole transit time between mouth and anus seems to be valid for three reasons: (I) in pigs on standard diets of cereals, the retention time of digesta in the colon corresponds to approximately $80 \%$ of the whole transit time (Keys \& De Barthe, 1974); (2) on the three diets used in this study and in constipation, the motility of the upper digestive tract remained unchanged except on the milk diet; in the latter instance spiking activity of the antrum was reduced so the gastric emptying rate probably was slower; (3) in cases of diarrhoea, whatever its aetiology, and of constipation in humans, the transit time between mouth and ileo-caecal valve remained unchanged and only the retention time in the large intestine was modified (Waller, 1975).

Dietary fibre, effects of bran and low-residue diets are subjects that have been investigated in pathological states in humans (Cummings, I973). The effects of dietary fibre upon transit time have been demonstrated (Cummings et al. 1978) but its effects on colonic motility have received less attention. Ingestion of bran reduced the intracolonic pressure and hence the motility index in patients with diverticular disease (Kirwan \& Smith, 1975).

In this study, bran increased the number of propulsive long spike bursts observed on a low-residue diet (milk-substitute) and decreased the occurrence of short spike bursts. However, one cannot directly compare the colonic motility in slow transit time investigated by pressure measurements in the pathological case of diverticular disease in man with that of slow transit time induced by a low-residue diet investigated by electromyography in normal pigs. The relationship between the weight of faeces and colonic motility indicates that one of the factors controlling colonic motility is the volume of the dietary residue entering the colon. The decrease of long spike burst number and the increase of short spike bursts observed on milk or milk and bran compared to standard diet might be attributed to some response to emptiness.

A role for colonic segmental activity in absorptive phenomena has been postulated frequently (Misiewicz, 1975). The increase in stool DM corresponding to an increase of short spike burst activity lends some support to this argument. However, this finding does not permit any firm conclusions because these changes were associated with an increased retention time in the colon.

Finally, the relationships between the two kinds of colonic electrical spiking activity and transit time demonstrated in the main part of this study were substantiated by the analysis of colonic performance in the extreme case of constipation.

\section{REFERENCES}

Canguilhem, R. \& Labie, C. (1977). Rev. Méd. vét. 128, 1669.

Castle, E. J. (1956). Br. J. Nutr. ro, I 5.

Clauss, W., Ehrlein, H. J. \& Hörnicke, H. (1978). Z. Gastroent. 16, 446.

Connell, A. M. (1962). Gut, 3, 342.

Connell, A. M. (1968). In Handbook of Physiology, sect. 6, vol. 4, p. 2075. Baltimore: Williams \& Wilkins Co.

Cummings, J. H. (1973). Gut 14, 69.

Cummings, J. H., Branch, W., Jenkins, D. J. A., Southgate, D. A. T., Houston, H. \& James, W. P. T. (1978). Lancet i, 5.

Fioramonti, J. \& Bueno, L. (1977). Ann. Rech. vét. 8, $28 \mathrm{I}$.

Heaton, K. W., Payler, D., Pomare, E. W. \& Harvey, R. F. (1974). Gastroenterology 66, 189. 
Keys, J. E. \& De Barthe, J. V. (1974). J. Anim. Sci. 39, 57.

Kirwan, W. O. \& Smith, A. N. (1975). Vth int. Symp. on Gastrointestinal Motility, Leuven, p. $10 \mathrm{I}$.

Latour, A. (1973). Ann. Rech. vét. 4, 347.

Misiewicz, J. J. (1975). Gut, 16, 311 .

Ruckebusch, Y. \& Bueno, L. (1976). Br. J. Nutr. 35, 397.

Spriggs, E. A., Code, C. F., Bargen, J. A., Curtiss, R. K. \& Hightower, N. C. (195I). Gastroenterology rg, 480.

Waller, S. L. (1975). Gut 16, 372. 